\title{
Os resíduos sólidos hospitalares na cidade de Eirunepé - Amazonas
}

\author{
Hospital solid waste in the city of Eirunepé - Amazonas
}

\author{
Charly Ferreira Menezes ', Nágila dos santos Situba "
}

\begin{abstract}
RESUMO
Nos dias atuais, o gerenciamento dos resíduos sólidos hospitalares tornou-se uma questão essencial para a saúde humana e para a preservação e conservação da natureza. Por este motivo, o acondicionamento, a coleta, o transporte, o tratamento e a disposição final são fases importantes, que possibilitam a promoção da saúde pública, bem-estar social e viabilidade econômica. Neste sentido, analisar o gerenciamento dos resíduos sólidos hospitalares na cidade de Eirunepé - Amazonas foi o objetivo deste estudo, que se apresenta como uma possibilidade de espacialização desta temática socioambiental. A cidade em estudo localiza-se a sudoeste da capital do Estado do Amazonas, possui 34.840 habitantes e densidade demográfica de 2,04 hab./km². O método utilizado para explicar a problemática foi o materialismo histórico e dialético, e a metodologia utilizada baseou-se em pesquisa documental e pesquisa de campo. Os resultados obtidos mostraram que, o Hospital Regional Vinicius Conrado não dispõe de um Plano de Gerenciamento de Resíduos de Serviços de Saúde (PGRSS); a cidade deposita todas as origens de resíduos sólidos em um lixão a céu aberto. Em relação ao saneamento básico, a cidade tem Estação de tratamento de Água, limpeza urbana, porém o esgoto da cidade não é tratado e vai diretamente para o rio Juruá.
\end{abstract}

Palavras-chave: Resíduos hospitalares; Lixão; Legislação; Eirunepé.

\section{ABSTRACT}

Nowadays, hospital solid waste management has become an essential issue for human health and for the preservation and conservation of nature. For this reason, the packaging, collection, transportation, treatment and final disposal are important phases that enable the promotion of public health, social welfare and economic viability. In this sense, analyzing the management of hospital solid waste in the city of Eirunepé - Amazonas was the objective of this study, which presents itself as a possibility of spatialization of the social and environmental theme. The city under study is located southwest of the capital of the state of Amazonas, has 34,840 inhabitants and a demographic density of 2.04 inhabitants / km2. The method used to explain the problem was historical and dialectical materialism, and the methodology used was based on documentary research and field research. The results showed that the Vinicius Conrado Regional Hospital does not have a Health Services Waste Management Plan (PGRSS); The city deposits all sources of solid waste in an open dump. Regarding basic sanitation, the city has a water treatment plant, urban cleaning, but the city's sewage is not treated and goes directly to the Juruá river.

\section{Keywords: Hospital waste; Dumping ground; Legislation; Eirunepé.}

' Graduado em Geografia, UEA. E-mail: charlymenezes16@hotmail.com. ORCID: https://orcid.org/0000-0003-2804-4374.

" Doutoranda em Geografia, UFF. E-mail: nagilasituba@hotmail.com. ORCID: https://orcid.org/0000-0003-4764-5394. 


\section{INTRODUÇÃO}

Nas últimas décadas, o município de Eirunepé vem apresentando um aumento populacional considerável, oriundo do processo de urbanização. Dados demográficos do Instituto Brasileiro de Geografia e Estatística (IBGE) mostram esse crescimento ao longo das décadas. No ano de 1990 residiam no município 20.372 habitantes, dez anos depois, em 2000, esse número aumentou para 26.074, e no último censo, em 2010, para 30.666. Estima-se que a população em 2019 seja de 35.273 habitantes.

Atrelado ao crescimento populacional está o aumento na geração de resíduos sólidos urbanos. "Dentre os problemas ambientais mais graves enfrentados pelas prefeituras, o saneamento e o lixo são os mais sérios, urgentes e os que causam maiores problemas, tanto para o meio ambiente quanto para saúde da população" (COSTA, 2004, p. 113). Entretanto, a solução dessa problemática deveria ser coletiva, mas não é, pois a população não colabora com a limpeza urbana da cidade e a gestão pública não gerencia como deveria.

Os resíduos sólidos urbanos gerados pelos serviços de saúde, uma vez não acondicionados, tratados, transportados, coletados e dispostos de maneira adequada, podem acarretar diversos problemas socioambientais. "O lixo, além de efeitos indesejáveis, como odor desagradável, intoxicação devido aos resíduos industriais e prejuízo à estética das paisagens, pode favorecer o surgimento de animais transmissões de doenças ao homem" (SANTOS et al., 2002, p.28). É comum o lixo atrair: moscas, mosquitos, baratas, formigas, roedores, suínos, cães e gatos, aves domésticas e urubus. Esse último animal é um indicador ambiental de disposição inadequada de lixo, e "sua presença é favorecida pelo alto percentual de matéria orgânica na composição gravimétrica nos lixões" (SILVA, OLIVEIRA \& SCHOR, 2008, p.5).

Apesar da existência de leis ambientais brasileiras, o gerenciamento dos resíduos sólidos continua sendo um problema a ser superado em pleno século XXI. Todavia, esses resíduos gerados e não tratados pelos serviços de saúde podem acarretar inúmeros danos à saúde física e mental dos Garis (sendo que estes quase sempre são desprovidos de 
técnicas de coleta). Diante das NBRs, esses resíduos deveriam ser descartados de acordo com o tipo e pelas condições físicas, pois podem causar danos à sociedade humana e ao meio ambiente.

Segundo a Agência Nacional de Vigilância Sanitária/ANVISA-RDC, $n^{\circ} 306$, de 7 de dezembro de 2004, a gestão dos resíduos de saúde deve ser planejada em um conjunto de procedimentos técnicos e científicos, o qual tem a finalidade de destinar esses resíduos perigosos de forma adequada. Infelizmente, em quase todas as cidades do Amazonas não há gerenciamento adequado dos resíduos hospitalares. Esse material é disposto em lixões a céu aberto, contaminando o lençol freático, poluindo rios e o ar atmosférico.

Neste viés, objetivou-se nesta pesquisa avaliar as 5 fases do gerenciamento dos resíduos sólidos hospitalares na cidade de Eirunepé - Amazonas, de modo a compreender as políticas públicas municipais, estaduais e federais no combate a destinação e disposição ambientalmente inadequadas.

Buscando alcançar o objetivo proposto, a pesquisa é de natureza aplicada, com uma abordagem qualitativa e quantitativa, tendo como ponto de partida as legislações específicas que tratam dos Resíduos dos Serviços de Saúde (RSS). Neste sentido, delimitou-se pesquisar apenas o gerenciamento dos resíduos hospitalares do Hospital Regional Vinicius Conrado, onde analisou-se os seguintes aspectos: acondicionamento, coleta, tratamento, transporte e disposição final.

Inicialmente foi realizado levantamento bibliográfico, coleta de dados secundários e primários nas instituições responsáveis pelo gerenciamento dos resíduos hospitalares, e trabalho de campo no hospital e lixão da cidade. Posteriormente, apresentaram-se questionamentos aos órgãos públicos e aos trabalhadores responsáveis pela coleta desses resíduos, no que se refere ao descumprimento da Resolução da Diretoria Colegiada (RDC), da Agência Nacional de Vigilância Sanitária (ANVISA), e da Resolução CONAMA, que dispõe sobre o Regulamento Técnico para o gerenciamento de resíduos sólidos do serviço de saúde. 
Segundo informações da direção geral do hospital, a produção mensal de resíduos de saúde no hospital é de $600 \mathrm{~kg}$, que são coletados duas vezes por semana por uma empresa contratada pela gestão pública. Os resíduos de saúde são coletados juntamente com os resíduos domiciliares, comerciais e de limpeza urbana. De acordo com a pesquisa de campo, os resíduos de saúde são dispostos em um vazadouro a céu aberto denominado como lixão. Segundo a Agência Nacional de Vigilância Sanitária (2004), os "resíduos químicos no estado sólido, quando não tratados, devem ser dispostos em aterro de resíduos perigosos - Classe I" (BRASIL, 2004). Diante disso, indaga-se por que a gestão do hospital regional não gerencia os resíduos hospitalares de maneira adequada na cidade de Eirunepé?

O hospital pesquisado está situado no Bairro Nossa Senhora de Aparecida, Rua Padre João Hosphel $\mathrm{s} / \mathrm{n}^{\circ}$, como pode ser visualizado na figura 1.

\section{Figura 1 - Localização da área de estudo}

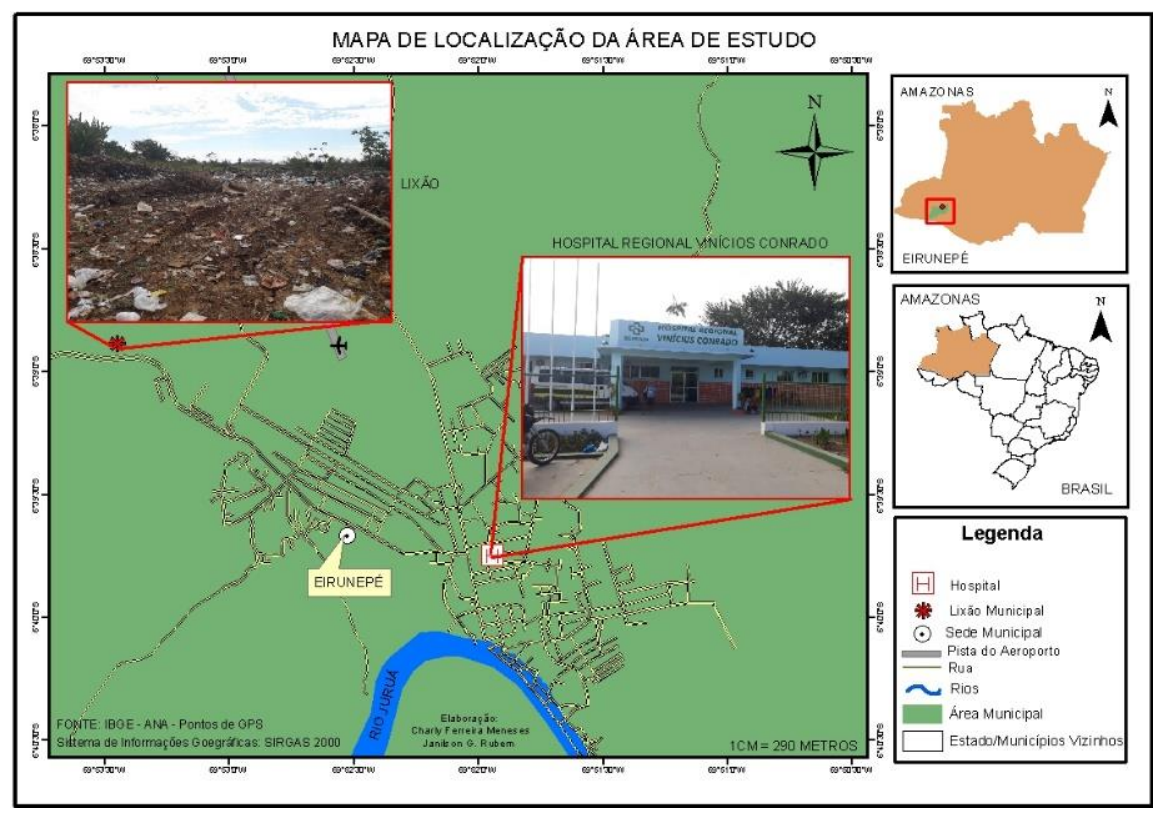

Fonte: Autores, 2019.

A cidade de Eirunepé possui apenas cinco estabelecimentos de saúde, sendo quatro Unidades Básicas de Saúde (UBS) e um Hospital Regional. Neste último, há internação pública, disponibilizando aos seus clientes 80 leitos, distribuídos em atendimento de 
urgência e emergência, clínica médica masculina e feminina, clínica obstétrica, clínica pediátrica, além de um centro cirúrgico que realiza procedimentos diariamente. Como o Hospital é regional de alta e média complexidade atende também pacientes de Envira, Itamarati e Ipixuna.

\section{OS RESÍDUOS HOSPITALARES: SEUS IMPACTOS NA SOCIEDADE E NO MEIO}

\section{AMBIENTE}

O Brasil é um dos grandes produtores de resíduos sólidos do mundo. Segundo a Associação Brasileira de Empresas de Limpeza Pública e Resíduos Especiais (ABBRELPE), em 2018, o Brasil gerou 79 milhões de toneladas de resíduos sólidos e apenas 72,7 milhões foram coletados. Além disso, apenas 59,5\% tiveram destinação em aterro sanitários (coletados 43,3 milhões de toneladas), e 40,5\% foram depositados em locais inadequados como lixões e aterros controlados (29,5 milhões de toneladas). De acordo com a ABRELPE, "para fazer frente todos os serviços de limpeza urbana no Brasil, os municípios aplicaram mensalmente, em média, $R \$ 10,15$ por habitante" (2019, p.11). No total, a limpeza urbana movimentou 28,1 bilhões na oferta do serviço nos municípios brasileiros. Esse serviço se caracteriza como essencial para a paisagem urbana e bem-estar social.

Historicamente, o lixo era considerado como sujeira ou coisas inúteis na antiguidade e na idade média, sendo assim, esse material não poderia ser reciclado ou reaproveitado. Na modernidade, o lixo é chamado de resíduos sólidos "aquilo que foi descartado e que, após o emprego de determinados processos, ou não, pode ser útil e aproveitado pelo homem (SANTOS et al., 2002, p.19).

A Política Nacional de Resíduos Sólidos (lei 12.305/2010) define resíduo sólido como sendo,

Material, substância, objeto ou bem descartado resultante de atividades humanas em sociedade e cuja destinação final se procede, se propõe proceder ou se está obrigado a proceder, nos estados sólidos ou semissólido, bem como gases contidos em recipientes e líquidos cujas particularidades tornem inviável o seu lançamento na rede pública de esgotos ou em corpos d'água, ou exijam para isso soluções técnicas ou economicamente inviáveis em face da melhor tecnologia disponível (BRASIL, 2010). 
O Conselho Nacional do Meio Ambiente define resíduos sólidos de serviços de saúde como "sendo todos aqueles resultantes de atividades exercidas nos serviços de saúde que por suas características necessitam de processos diferenciados em seu manejo, exigindo ou não tratamento prévio à sua disposição final" (BRASIL, 2005).

A resolução do CONAMA, $\mathrm{n}^{\circ}$ 358, de 29 de abril de 2005, que dispõe sobre o tratamento e a disposição final dos resíduos dos serviços de saúde, aplicando-se a todos os serviços relacionados com o atendimento à saúde humana ou animal, determina que:

Os geradores de resíduos de serviços de saúde em operação ou a serem implantados, devem elaborar e implantar o Plano de Gerenciamento de Resíduos de Serviços de Saúde-PGRSS, de acordo com a legislação vigente, especialmente as normas da vigilância sanitária. A resolução profere ainda que cabe aos geradores de resíduos de saúde e ao responsável legal o gerenciamento dos resíduos desde a geração até a disposição final de forma a atender aos requisitos ambientais e de saúde pública e saúde ocupacional sem prejuízo de responsabilização solidária de todos aqueles, pessoas físicas e jurídicas que, direta ou indiretamente, causem ou possam causar degradação ambiental, em especial os transportadores e operadores das instalações de tratamento e disposição final (BRASIL, 2005).

O gerenciamento inadequado dos resíduos sólidos oriundos de serviços de saúde pode causar danos irreparáveis a natureza e à sociedade. Por esse motivo, a Agência Nacional de Vigilância Sanitária (ANVISA), em conformidade com o CONAMA, instituiu em 07 de dezembro de 2004 a RDC, $n^{\circ}$ 306, que dispõem a respeito do regulamento técnico para o gerenciamento de resíduos de serviços de saúde. Essa RDC autoriza o órgão de vigilância sanitária do estado, dos municípios e do distrito federal, a estabelecerem normas de caráter supletivo ou complementar a fim de adequar o regulamento técnico às especificidades de cada local.

As legislações que tratam a respeito dos resíduos de serviço da saúde determinam que todos os geradores desses resíduos são responsáveis pelo seu correto gerenciamento, desde o momento de sua geração até a destinação final. Assim sendo, os geradores desses resíduos precisam elaborar e implantar o Plano de Gerenciamento de Resíduos de Serviços de Saúde (PGRSS), baseado nas características dos resíduos gerados e na classificação desses resíduos. 
Esses PGRSS devem estar de acordo com as normas locais relativas à coleta, transporte e disposição final desse tipo de resíduo. Nos PGRSS constam as ações relativas ao manejo dos resíduos, observando suas características e riscos, no âmbito dos estabelecimentos, contemplando os aspectos referentes a geração, a segregação, o acondicionamento, a coleta, o transporte, o tratamento e a disposição final, bem como as ações de proteção à saúde pública e ao meio ambiente.

Nas últimas décadas, a crescente demanda por serviços de saúde fez surgir uma nova preocupação: qual a melhor forma de gerenciar os resíduos gerados por esses serviços, tendo em vista que uma disposição inadequada pode acarretar grandes prejuízos econômicos, sociais, culturais e ambientais?

Segundo Coutinho e Carvalho (2007), os cuidados a serem tomados com os resíduos de saúde estão amplamente apresentados nas recomendações da ANVISA, RDC e CONAMA. Nesse contexto, a prevenção a ser tomada diminui os riscos de propagação de agentes bacterianos e virais, que podem estar presentes nos resíduos do serviço de saúde, principalmente os infectantes e perfurocortantes, capazes de tornar-se fonte de disseminação de doenças, levando prejuízos ao meio ambiente. Segundo a Organização Mundial de Saúde (OMS),

Cerca de $75 \%$ a $90 \%$ dos resíduos de serviços de saúde podem ser considerados similares aos resíduos urbanos. Contudo, $10 \%$ a $25 \%$ restante apresentam risco à saúde pública e ao meio ambiente pela presença de organismos patogênicos, perfuro cortantes, substâncias químicas, medicamentos e substâncias genotóxicas, necessitando, dessa forma, de soluções técnicas específicas (MENEZES, 2008).

Neste viés, os resíduos domiciliares apresentam características semelhantes aos resíduos hospitalares, no que se refere ao nível de periculosidade. Assim sendo, o cuidado com qualquer tipo de resíduo é necessário e indispensável. 


\section{GERENCIAMENTO DOS RESÍDUOS HOSPITALARES NA CIDADE DE EIRUNEPÉ -}

AMAZONAS

Na pesquisa realizada no Hospital Regional Vinicius Conrado identificou-se que, a instituição não dispõe de um Plano de Gerenciamento de Resíduos de Serviços de Saúde (PGRSS). A rigor, essa irregularidade impossibilita que o gerenciamento dos Resíduos de saúde seja realizado de forma compatível com o que as legislações brasileiras impõem, podendo acarretar riscos ao meio ambiente e a população Eirunepeense.

A Resolução $n^{\circ}$ 306, de 07 de dezembro de 2004, que dispõe sobre o regulamento técnico para o gerenciamento dos resíduos de serviços de saúde determina que:

O gerenciamento desses constitui-se em um conjunto de procedimentos de gestão, planejados e implementados a partir de bases científicas e técnicas, normativas e legais, com o objetivo de minimizar a produção de resíduos e proporcionar aos resíduos gerados um encaminhamento seguro, de forma eficiente, visando a proteção dos trabalhadores, a preservação da saúde pública, dos recursos naturais e do meio ambiente (BRASIL, 2004).

As etapas e procedimentos técnicos a serem seguidos no manejo dos RSS precisam ser compatíveis com a legislação. A maneira como esses resíduos são tratados no Hospital Regional Vinicius Conrado será apresentada a seguir:

A segregação consiste na separação dos resíduos no momento de sua geração, de acordo com as características físicas, químicas e biológicas. No hospital pesquisado, a segregação é feita pelos funcionários que trabalham como auxiliares de serviços gerais. Esses profissionais são desprovidos de treinamento técnico e Equipamentos de Proteção Individual (EPI), mesmo assim, eles são incumbidos de coletar e separar os RSS.

No que se refere ao acondicionamento, a legislação estabelece que no ato de embalar, os resíduos segregados sejam colocados em sacos ou recipientes que evitem vazamento e resistam às ações de punctura e ruptura. A capacidade dos recipientes de acondicionamento deve ser compatível com a geração diária de cada tipo de resíduo. $\mathrm{Na}$ pesquisa de campo, constatou-se que, após serem usados, os resíduos de saúde são dispostos dentro de lixeiras com sacolas plásticas. Se forem resíduos perfurocortantes em 
destarte, a etapa de identificação consiste no conjunto de medidas que permite o reconhecimento dos resíduos contidos nas sacolas e recipientes, fornecendo informações ao correto manejo dos RSS.

No hospital pesquisado, os resíduos perfurocortantes são armazenados em destarte e todo o restante em sacolas plásticas ou caixa de papelão, sem identificação. O transporte interno consiste no traslado dos resíduos do ponto de geração até o local destinado ao armazenamento temporário ou externo.

Cabe aos auxiliares de serviços gerais a função de coletar os resíduos nos pontos de geração e levar até o local destinado ao armazenamento temporário. A figura abaixo mostra o local onde é armazenado os resíduos de saúde do hospital estudado.

Figura 2 - Armazenamento dos resíduos hospitalares.

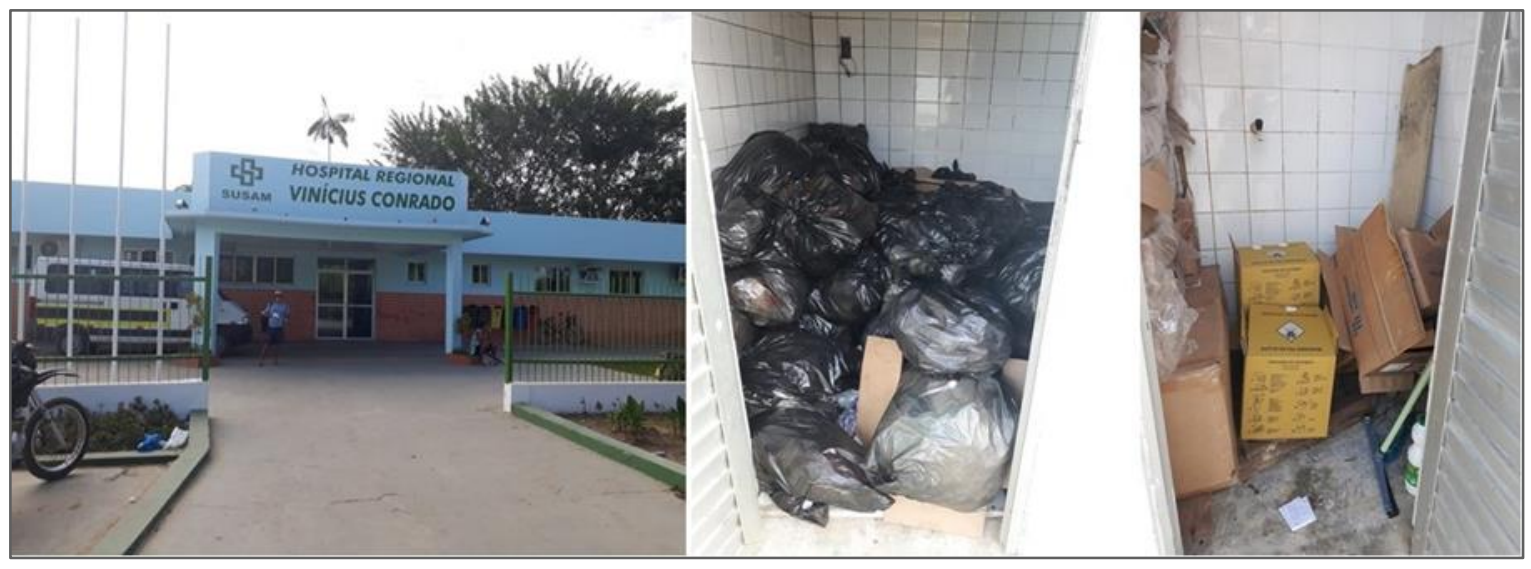

Fonte: Autores, 2019.

Esse é o local onde os resíduos hospitalares ficam armazenados até os trabalhadores da limpeza urbana realizar a coleta. Essa coleta depende exclusivamente dos agentes de limpeza, pois no hospital não há técnicos especializados na área de armazenamento, coleta e tratamento dos RSS.

Em relação ao tratamento, essa etapa consiste na aplicação de métodos, técnicas ou processos que modificam as características dos riscos inerentes aos resíduos, reduzindo ou eliminando o risco de contaminação, de acidentes ocupacionais ou de dano ao meio ambiente. Os resíduos produzidos no hospital Vinicius Conrado não passam por nenhum 
tipo de procedimento relacionado ao tratamento. $\mathrm{O}$ armazenamento externo consiste em manter esses resíduos em recipientes fechados até a realização da etapa de coleta. Todavia, nem sempre esses produtos de pós-consumo são armazenados, às vezes, são dispostos diretamente no piso cimentado.

A etapa de coleta e transporte é a remoção dos RSS do abrigo (armazenamento externo) até a disposição final. Como já mencionado antes, a coleta dos RSS é realizada duas vezes por semana por uma empresa terceirizada. Os trabalhadores e veículos que realizam a coleta dos resíduos domiciliares e limpeza urbana são os mesmos que coletam os resíduos sólidos de saúde. De acordo com a direção do hospital, é disponibilizado aos trabalhadores da coleta: luvas, máscaras e álcool para que eles lavem as mãos após o contato com os resíduos. Segundo o CONAMA (2005), a disposição final de resíduos de serviços de saúde é a prática de dispor os resíduos no solo previamente preparado para recebê-los, mediante critérios técnico-construtivos e operacionais adequados, em consonância com as exigências dos órgãos ambientais competentes.

Conforme a Associação Brasileira de Empresas de Limpeza Pública e Resíduos Especiais (ABRELPE), em 2015, no Brasil, 60\% das cidades encaminharam 30 milhões de toneladas de resíduos sólidos para locais irregulares. Isso significa que, apesar da existência da Política Nacional de Resíduos Sólidos (lei 12.305/2010), as cidades brasileiras continuam dispondo inadequadamente o esse produto de pós-consumo.

A cidade de Eirunepé não dispõe de aterro sanitário para destinação e disposição ambientalmente adequada dos resíduos sólidos. Assim sendo, os resíduos são dispostos no lixão, que fica localizado no bairro de Fátima - estrada do Xidá (Figura 3). "Entretanto, no Brasil, até hoje, a maior parte (76\%) dos resíduos recolhidos nos centros urbanos é simplesmente jogada sobre o solo nos lixões (depósito a céu aberto) ou no vazadouro existente na periferia das cidades [...]" (SANTOS et al., 2002, p. 21). 
Figura 3 - Disposição final dos resíduos da saúde na cidade de Eirunepé - Amazonas

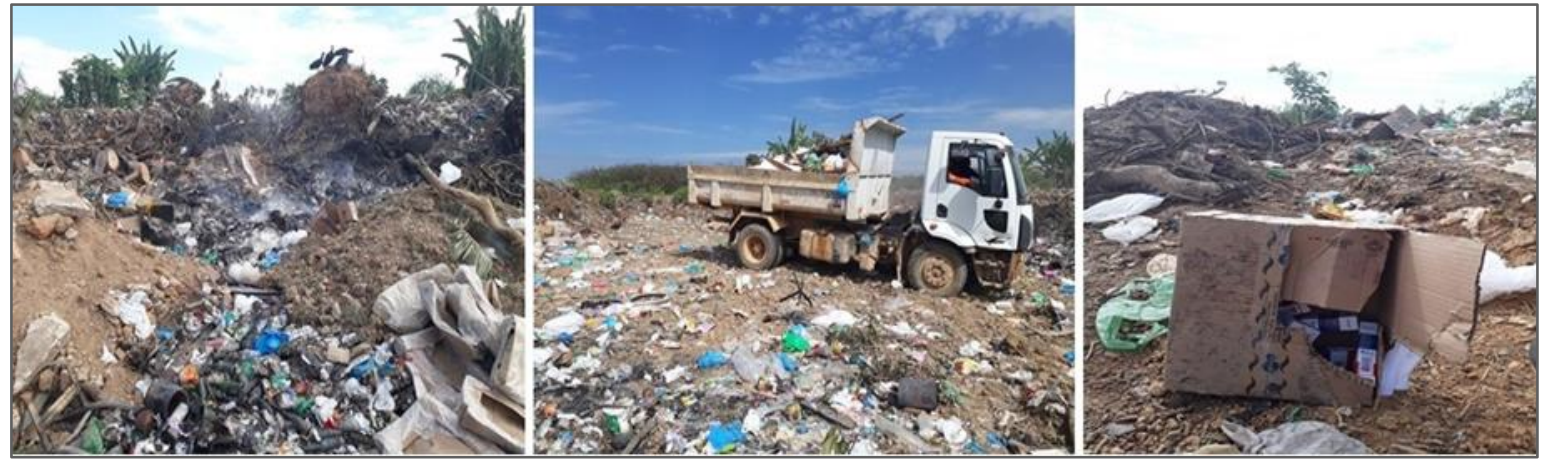

Fonte: Autores, 2019.

Na pesquisa de campo identificou-se que os RSS do hospital Regional Vinicius Conrado são coletados duas vezes por semana pela empresa ELFA COMÉRCIO E SERVIÇOS LTDA. Essa empresa também é encarregada de realizar a coleta de resíduos urbanos, por isso os servidores e veículos que fazem a coleta urbana são os mesmos que realizam a coleta dos RSS. Verificou-se que, após o despejo desses resíduos no solo, eles são queimados e seus restos se unem aos outros resíduos.

\section{RESULTADOS E DISCUSSÕES}

O Plano de Gerenciamento de Resíduos Sólidos de Saúde (PGRSS) é muito importante para que os RSS de uma determinada instituição obtenha destinação e disposição final adequada. De acordo com a resolução $n^{\circ}$ 306, de 7 de dezembro de 2004, esse plano deve ser criado pelo próprio gerador desses resíduos, obedecendo a critérios técnicos, legislação ambiental, normas de coleta e transporte dos serviços locais de limpeza urbana e outras orientações contidas no regulamento (BRASIL, 2004).

O Hospital Regional Vinicius Conrado ainda não criou o seu PGRSS. Desta forma, os RSS gerados na instituição não passam por um processo de gerenciamento adequado, fato que põe em risco a integridade física das pessoas que trabalham com esses resíduos, dos moradores que residem próximo ao local de disposição final, e das pessoas que frequentam o lixão diariamente. 
O manejo dos RSS abrange as etapas de segregação, acondicionamento, identificação, transporte interno, armazenamento temporário, tratamento, armazenamento externo, coleta, transporte externo e disposição final. Todas essas etapas devem ser/estar prescritas no PGRSS e serem seguidas de acordo com as normas locais.

Durante a coleta de dados nas instituições, pôde-se observar o desrespeito por parte dos órgãos responsáveis pelo manejo dos RSS, com as pessoas que trabalham com esses resíduos, e a irresponsabilidade da municipalidade com a conservação e preservação do ambiente urbano e ambiental.

Em visitas ao hospital e ao lixão da cidade de Eirunepé, foi possível encontrar estruturas incompatíveis com as legislações e funcionários trabalhando sem o mínimo de qualificação para o manejo desses resíduos (sem equipamentos de proteção individual). Além disso, ao lado do lixão da cidade foi possível identificar a criação de gado bovino, isso significa que, dependendo do tipo de alimento que esses animais comem e da água que bebem, certamente, poderão estar contaminados.

Esse descaso com o meio ambiente e com a população pode ser minimizado com a criação de um Plano de Gerenciamento de Resíduos de serviços de Saúde (PGRSS) por parte do hospital, assim como a construção de um aterro sanitário pode facilitar que os RSS tenham destinação correta.

\section{CONCLUSÕES}

O presente trabalho poderá contribuir com a criação de políticas públicas municipais relacionadas ao gerenciamento adequado dos resíduos sólidos e na compreensão do espaço social eirunepeense. Assim sendo, esse trabalho teve como principal objetivo analisar o processo de gerenciamento dos resíduos sólidos hospitalares do Hospital Regional Vinicius Conrado, buscando confrontar os passos seguidos no manejo desses resíduos com os elementos e etapas estabelecidos pelas legislações da área.

Identificou-se que a falta de um plano de gerenciamento de resíduos sólidos hospitalar implica de forma negativa no manejo desses resíduos dentro e fora da unidade, 
impossibilitando que o gerenciamento seja feito em consonância com o que as legislações dispõem.

A falta de treinamento das pessoas envolvidas no tratamento e coleta, a falta de equipamentos de proteção individual e coletivos, falta de locais apropriados para o armazenamento dos resíduos, entre outros, também fazem com que os resíduos não recebam um tratamento adequado.

Quanto à disposição final a pesquisa de campo identificou que os resíduos são dispostos diretamente no lixão da cidade e depois de queimados são compactados junto aos resíduos urbanos. Desta forma, conclui-se que os resíduos sólidos hospitalares do hospital de Eirunepé-AM estão causando impactos ambientais e sociais no município.

\section{AGRADECIMENTOS}

Agradeço à Universidade do Estado do Amazonas - UEA.

\section{REFERÊNCIAS}

ABRELPE. Panorama dos resíduos sólidos no Brasil. 2018/2019. Disponível em: http://abrelpe.org.br/download-panorama-2018-2019/. Acesso: 30/08/2019.

ABRELPE. Panorama dos resíduos sólidos no Brasil. 2015. Disponível em: http://abrelpe.org.br/download-panorama-2015/. Acesso: 30/08/2019.

ABRELPE. Panorama dos resíduos sólidos no Brasil. 2016. Disponível em: http://abrelpe.org.br/download-panorama-2016/. Acesso: 30/08/2019.

ABRELPE. Estimativas dos custos para viabilizar a universalização da destinação adequada de resíduos sólidos no Brasil. São Paulo, junho de 2015. Disponível em: file:///C:/Users/Cleocivan/Desktop/Artigo\%20Charly/estimativa_dos_custos.pdf. Acesso: 30/08/2019.

BRASIL. Resolução ANVISA RDC No 306/2004. Disponível em: http://portal.anvisa.gov.br/documents/33880/2568070/res0306_07_12_2004.pdf/95eac678d441-4033-a5ab-f0276d56aaa6. Acesso: 08/09/2019. 
BRASIL. Política Nacional de Resíduos Sólidos (Lei $n^{\circ}$ 12.305/2010). Disponível em: http:/www.planalto.gov.br/ccivil_03/ato 1to 2007-2010/lei/12305.htm. Acesso: 09/08/2018.

BRASIL. Resolução $\mathbf{n} 358,29$ de abril de 2005. Disponível em: http://www.siam.mg.gov.br/sla/download.pdf?idNorma=5046. Acesso: 09/08/2019.

CALDERONI, Sabetai. Os bilhões Perdidos no Lixo. 4.ed. São Paulo: Humanitas Editora FFLCH/USP, 2003.

COUTINHO, R. S. S.; CARVALHO, A. M.. Discutir a relação: resíduos de serviço de saúde, impactos ambientais e ação educativa. Candombá Revista Virtual, v. 3, p. 81-14, 2007. Disponível em: http://www.mpdft.mp.br/saude/images/Meio_ambiente/Discutir_rela\%C3\%A7\%C3\%A3o.pdf. Acesso: 28/07/2019.

COSTA, Marcus A.G.. Poluição ambiental: herança para gerações futuras. Santa Maria: Orium, 2004.

GOMES, Paulo César da Costa. Geografia e modernidade. Rio de Janeiro: Bertrand Brasil, 1996.

LEFEBVRE, Henri. A vida cotidiana no mundo moderno. São Paulo: Ática, 1991.

MENEZES, S. H. da C. Tratamento e disposição final de resíduos de medicamentos quimioterápicos e de rejeitos radioterápicos: Estudo comparativo entre a legislação internacional e a brasileira. Dissertação de Mestrado em Saúde Pública, Fiocruz, 2008.

SANTOS, Maria Cristina dos; TOPAN, Claúdia Saldanha de Oliveira; LIMA, Ellen Rabelo. Lixo: curiosidades e conceitos. Manaus: Editora da Universidade Federal do Amazonas, 2002.

SANTOS, Milton. Técnica, Espaço, Tempo: Globalização e Meio Técnicos-científicoinformacional. 5 ed. - São Paulo: Editora da Universidade de São Paulo, 2013.

SANTOS, Milton. Pobreza Urbana. 3.ed. São Paulo: Editora da Universidade de São Paulo, 2013.

SANTOS, Milton. Espaço e método. 5 ed. - São Paulo: Editora da Universidade de São Paulo, 2014.

SANTOS, Milton. Urbanização Brasileira. 5 ed. - São Paulo: Editora da Universidade de São Paulo, 2018.

SANTOS, Milton. Metamorfose do espaço habitado: fundamentos teóricos e metodológicos da geografia. 5 ed. - São Paulo: Editora da Universidade de São Paulo, 2014.

SANTOS, Milton. Da totalidade ao lugar. 1 ed. - São Paulo: Editora da Universidade de São Paulo, 2014. 
SANTOS, Milton. Por uma outra globalização: do pensamento único à consciência universal. Rio de Janeiro: Record, 2008.

SANTOS, Milton. A natureza do Espaço: Técnica e Tempo, Razão e Emoção. 4 ed. - São Paulo: Editora da Universidade de São Paulo, 2017.

SANTOS, Milton; SILVEIRA, Maria Laura. O Brasil: território e sociedade no início do século XXI. São Paulo, Editora Record, 2001.

SANTOS, Milton. O espaço dividido: Os dois circuitos da Economia urbana dos países subdesenvolvidos. 2 ed. - São Paulo: Editora da Universidade de São Paulo, 2018.

SCHOR, Tatiana; MORAES, A. O. 0 papel dos núcleos urbanos na manutenção da vida. In: Gustavo Viera Peixoto Cruz; Saulo Andrade. (Org.). Rio Negro, Manaus e as Mudanças no Clima. São Paulo: Instituto Sociambiental, 2008, v., p. 47-52.

SCHOR, Tatiana. As cidades invisíveis da Amazônia Brasileira. Mercator (Fortaleza. Online), v. 12, p. 67-84, 2013.

SILVA, Alexandre D.; OLIVEIRA, J. A. ; SCHOR, Tatiana. Entre rios, florestas e urubus: para onde vai o lixo das cidades na Amazônia?. In: IV Encontro da Associação Nacional de Pesquisa e PósGraduação em Ambiente e Sociedade IV ENANPPAS, 2008, Brasília. Anais do IV Encontro da Associação Nacional de Pesquisa e Pós-Graduação em Ambiente e Sociedade IV ENANPPAS, 2008.

RODRIGUES, A. M.. Produção e Consumo do e no Espaço - Problemática Ambiental Urbana. $1^{\circ}$. ed. São Paulo: Hucitec, 1998. 240 p. 